\title{
A Diachronic Approach to the Motive of Crypto-Functions of Formal Markers in English
}

\author{
Baohua Dong ${ }^{1 \& 2}$ \\ ${ }^{1}$ College of International Studies, Southwest University, Chongqing, China \\ ${ }^{2}$ College of Foreign Languages, Chongqing University of Science \& Technology, Chongqing, China \\ Correspondence: Baohua Dong, Southwest University, No. 2 Tiansheng Road, Beibei, Chongqing, China. E-mail: \\ sisudbh@163.com
}

$\begin{array}{ll}\text { Received: October 15, } 2015 & \text { Accepted: November 10, } 2015 \quad \text { Online Published: May 18, } 2016 \\ \text { doi:10.5539/ells.v6n2p161 } & \text { URL: http://dx.doi.org/10.5539/ells.v6n2p161 }\end{array}$

\begin{abstract}
This paper, based on the exploration of crypto-functions of formal markers in English (Dong, 2016), preliminarily attempts to explicate the motive of their crypto-functions in systemic functional framework through a diachronic approach. The study firstly claims that formal markers can be treated as one of multiple linguistic expressions deployed for constructing the experiential phenomenon. Then the study assumes that the motive of crypto-functions of formal markers can be revealed from the diachronic conventionalization of multiple linguistic expressions towards formal markers in their process of experience construction. And such an assumption has then been tested with the distribution frequencies of formal markers in Corpus of Historical American English (COHA). It is found that, with the diachronic increase of the distribution frequencies of formal markers in COHA, the diachronic conventionalization of multiple linguistic expressions towards formal markers does exist, and that such a conventionalization is then attributed to language chunk composed of formal markers together with other following elements and renders formal markers prefabricate potential, thus resulting in their crypto-functions.
\end{abstract}

Keywords: formal markers, crypto-function, prefabricate potential

\section{Introduction}

Literatures in Systemic Functional Linguistics (SFL) often claim that formal markers like meteorological it and existential there are devoid of experiential function. In consequence, the rationale of why formal markers are embodied in language system tends to be explicated in terms of their interpersonal function as Subject and textual function as Theme. However, the definitions of Theme (cf. Halliday \& Matthiessen, 2014) and Subject (cf. Fawcett, 1999) both indicate that Theme and Subject are presupposed by their experiential function. Therefore, the functional explanations of formal markers have not been congruent in SFL. In light of such a dilemma, Dong \& Wang (2016) propose a functional model, the centrality of which is that any experientially compulsory element in a clause should have three metafunctions simultaneously in terms of Rank Constituent Criteria (cf. Halliday, 1994). In the meantime, given that formal markers have the reactance that their counterparts - non-formal markers-lack, formal markers can be treated as the crypto-category (See Whorf, 1956) and their functions can hereby be analyzed as crypto-functions (See Dong, 2016). This paper, however, goes ever further in an attempt to locate the motive of crypto-functions of formal markers, to be specific, the motive of their experiential crypto-functions. Generally, two perspectives in terms of language system can be resorted to address this issue, that is, an external perspective and an internal perspective, the latter of which, concerned about language choices within language system, will be mainly discussed in this study.

\section{How to Locate the Motive of Crypto-Functions of Formal Markers}

\subsection{Formal Markers and Experiential Phenomenon with Multiple Linguistic Expressions}

The experiential phenomenon with multiple linguistic expressions refers to those experiential phenomena that can be construed by at least three types of wordings in transitivity system. For example, the experiential phenomenon of "rain falling down" can be construed by "it is raining", "the rain is pouring down", and "we had a downpour". Surely, the expression "it is rainy" can also be used, and even the expression "the rain rains" (COHA_1940_NF) still exists. The following will address the issue of formal markers as one of multiple 
linguistic expressions for experience construction.

To date, Halliday \& Matthiessen $(2004,2014)$ and Langacker (1991) have discussed formal markers in their construction of the experiential phenomenon, though they have not mentioned the term like the experiential phenomenon with multiple linguistic expressions. According to Halliday \& Matthiessen (2004, pp. 258-259; 2014, p. 310), the experiential phenomenon weather can be construed by "existential there structure", "material process", "relational process" and "meteorological it together with $v$-ing". See Table 1.

Table 1. The construe of the experiential phenomenon "weather"

\begin{tabular}{lll}
\hline & Means of Construing Weather & Example \\
\hline (i) & existential there structure & There was a storm/hurricane/breeze/gale/shower/blizzard \\
(ii) & material process & The wind's blowing; The sun's shining; The clouds are coming down \\
(iii) & relational process & It's foggy/cloudy/misty/hot/humid/sunny/frosty \\
(iv) & meteorological it together with $v$-ing & It's raining/hailing/snowing/freezing/pouring/drizzling/lightning/thundering \\
\hline
\end{tabular}

In the similar vein, Langacker (1991) has also addressed the construe of weather, especially "the rain". According to Langacker, the multiple linguistic expressions for a certain experiential phenomenon result from "an incongruence between the global character of the occurrences they describe and the analytical nature of the syntactic structures available to code them" (1991, pp. 365-366). In this case, the distinction among Circumstance, Process and Participants is not clear when some syntactic structures are used to encode the experiential phenomenon. For instance, experiential phenomenon "rain", due to the constraints of different construal, is embodied by different grammatical categories and structures. See Table 2.

Table 2. Different grammatical categories and structures in construing experiential phenomenon "rain"

\begin{tabular}{llll}
\hline & Means of construing & Meaning & Example \\
\hline (i) & as a verb & fall down from the sky & It rains; Rain rains; \\
(iia) & as a noun & emphasize the rain itself & Some rain came through the window; \\
(iib) & as a noun & nominalization & The rain continued; We had a good rain; \\
(iic) & as a noun & emphasize the material process of rain & Rain falls; It falls rain \\
\hline
\end{tabular}

In terms of above discussion, it is easy to see the similarity between Halliday \& Matthiessen (2014) and Langacker (1991), but the difference is also obvious: (iia) and (iib) in Langacker (1991) are treated as the same type in Halliday \& Matthiessen (2014), that is, the material process construction. In addition, Langacker (1991) fails to mention the relational process and existential process construction proposed in Halliday \& Matthiessen (2014).

Compared with the discussion on construction of experiential phenomenon weather, the experiential phenomenon existence has seldom been addressed. But the relevant discussions can still remind us of how to locate the means of the construction of the experiential phenomenon existence in literature. For example, three means of construing the experiential phenomenon existence can be obtained in Halliday \& Matthiessen (2014, p. 309). See Table 3.

Table 3. Means of construing the experiential phenomenon "existence"

\begin{tabular}{lll}
\hline & Means of Construing & Example \\
\hline (i) & relational process & A (The) picture is on the wall. \\
(ii) & existential there together with verb & There was a picture on the wall. \\
(iii) & combination of (i) and (ii) with existential there omitting & On the wall (there) was a Picasso painting. \\
\hline
\end{tabular}

\subsection{Crypto-Functions and the Conventionalization of Multiple Linguistic Expressions towards Formal Markers}

In SFL that language is as it is depends on its function, and there is no exception to formal markers. But this only addresses the function itself with no mention of the motive of functions. The discussion of the motive of functions, however, seems no easy endeavor.

First of all, the language choice in language system is determined by its function. In SFL, language is designed to fulfill three metafunctions: an experiential metafunction for relating experience, an interpersonal metafunction 
for creating interpersonal relationships, and a textual metafunction for organizing information. In this case, to locate the motive of function means exploring what makes human beings describe the world, promote interpersonal relation, and construct the text, which is indeed a tough nut to crack.

Secondly, due to its intra-organism stance, SFL disclaims the cognitive approach to language. Thus in SFL the motive of functions of formal markers cannot be attributed to cognitive language users, though SFL does not object to other disciplines that adopt a cognitive approach to language research. As indicated in Martin (2013, p. 167), SFL does not adapt the cognitive approach to language, for the cognitive approach towards language study, in SFL mind's eye, is still based on language itself, ultimately falling victim to a vicious circle.

What's worse, when it comes to crypto-function, things become even more complicated. Besides the above two difficulties, formal markers have their own problems. As indicated in Dong (2016), crypto-function lies in the reactance of formal markers as crypto-categories, which other non-formal markers lack. For example, formal marker there cannot be queried, theme-predicated or theme-identified while its counterpart locative there can. Therefore, crypto-function is the further abstraction of metafunction, which makes the exploration of the motive of formal markers even harder. However, the exploration of motive of crypto-functions is unlike that of metafunctions. The latter is somewhat concerned about the ontological issue, while the former is an epistemological one, which can thus be observed through comparison between metafunction and crypto-function, that is, the rationale of how formal markers have obtained the reactance that their counterpart haven't. In this case, unlike the discussion of the motive of metafunctions for those non-formal markers, I assume that the motive of crypto-function can be observed through the multiple linguistic expressions of experiential phenomenon towards the conventionalization, that is, formal markers. This is because formal markers, as one of multiple linguistic expressions (cf. §2.1), tend to be conventionalized to be like language chunks in their construction of experiential phenomenon, which makes formal markers further separate from the deictic non-formal markers and hereby results in the experiential crypto-function with the character of reactance (See Whorf, 1956). And the next section will test whether such an assumption makes sense by resorting to the data from a diachronic corpus.

\section{The Procedures of Exploring the Motive to Crypto-Function of Formal Markers}

\subsection{Data Collection and Analysis}

As indicated in 2.2, the crypto-function can be observed through the conventionalization of the multiple linguistic expressions towards formal markers in their process of construing the experiential phenomenon. In this section, Corpus of Historical American English (COHA) is used to collect data. COHA, as a diachronic corpus, has collected 400 million words of 200 years ranging from 1810 to 2009 in the interval of 10 years. However, among the four genres in COHA, only fiction data is leveled in each 10 year, accounting for $48 \%$ to $55 \%$ of total data in COHA. Fortunately, fiction data still boasts 200 million words, which can serve as a good database to observe the distribution frequencies of formal markers. See Table 4.

Table 4. General description of fiction datain COHA

\begin{tabular}{llllllll}
\hline Year & Fiction & Total & Proportion & Year & Fiction & Total & Proportion \\
\hline $1810 \mathrm{~s}$ & 641,164 & $1,181,022$ & 0.54 & $1910 \mathrm{~s}$ & $11,935,701$ & $22,655,252$ & 0.53 \\
$1820 \mathrm{~s}$ & $3,751,204$ & $6,927,005$ & 0.54 & $1920 \mathrm{~s}$ & $12,539,681$ & $25,632,411$ & 0.49 \\
$1830 \mathrm{~s}$ & $7,590,350$ & $13,773,987$ & 0.55 & $1930 \mathrm{~s}$ & $11,876,996$ & $24,413,247$ & 0.49 \\
$1840 \mathrm{~s}$ & $8,850,886$ & $16,046,854$ & 0.55 & $1940 \mathrm{~s}$ & $11,946,743$ & $24,144,478$ & 0.49 \\
$1850 \mathrm{~s}$ & $9,094,346$ & $16,493,826$ & 0.55 & $1950 \mathrm{~s}$ & $11,986,437$ & $24,398,180$ & 0.49 \\
$1860 \mathrm{~s}$ & $9,450,562$ & $17,125,102$ & 0.55 & $1960 \mathrm{~s}$ & $11,578,880$ & $23,927,982$ & 0.48 \\
$1870 \mathrm{~s}$ & $10,291,968$ & $18,610,160$ & 0.55 & $1970 \mathrm{~s}$ & $11,626,911$ & $23,769,305$ & 0.49 \\
$1880 \mathrm{~s}$ & $11,215,065$ & $20,872,855$ & 0.54 & $1980 \mathrm{~s}$ & $12,152,603$ & $25,178,952$ & 0.48 \\
$1890 \mathrm{~s}$ & $11,212,219$ & $21,183,383$ & 0.53 & $1990 \mathrm{~s}$ & $13,272,162$ & $27,877,340$ & 0.48 \\
$1900 \mathrm{~s}$ & $12,029,439$ & $22,541,232$ & 0.53 & $2000 \mathrm{~s}$ & $14,590,078$ & $29,479,451$ & 0.49 \\
\hline
\end{tabular}

Note that COHA is an online corpus, which cannot be retrieved by regular expression. Therefore, the retrieval expression can only be made by reference to CLAWS7 Tagset. As to meteorological $i t$ structure, if there is no limit to the verb and the retrieval expression "it [ $\left.\mathrm{vb}^{*}\right]$ " is used, there will be 922,141 results, most of which are not meteorological it structures. And the painstaking efforts should be devoted to get rid of those non-meteorological it structures. In this case, I choose as the objectives the words like "rain", "snow", "hail", "freeze", "drizzle", "thunder", according to the discussion of the meteorological verbs in Sinclair (1990) and 
Levin (1993). For one thing, these words, compared with other meteorological words, enjoy high distribution frequencies in COHA; for another, these words can be used as verbs and also have their adjective forms. Note that the description of "wind" often resorts to verb "blow", and in the meantime "wind", when used as verb, does not mean "weather", which is thus omitted.

After a comprehensive analysis of meteorological it structures, I decide the following three retrieval expressions in terms of the tense of verbs, the modification of adverbs, and the adjective predicative. Let's take "rain" as an example.

(1) it [rain]

(2) it [vbdz]|[vbz]|[vbg]|[vm]|[rr] [rain]

(3) it $[\mathrm{vbdz}] \mid[\mathrm{vbz}]$ rainy

Retrieval expression (1) indicates meteorological it structures with any form of verb "rain", including simple present, simple past, etc. Retrieval expression (2) describes meteorological it structures with any modification between meteorological "it" and verb "rain". Retrieval expression (3) means meteorological it structures with "it" and "rainy" in simple past or simple present. It should be mentioned that words such as "hail", "freeze", "drizzle", "thunder" have the same forms in both present in present and adjective predicative, and the results by retrieval expression (2) include part of the results of retrieval expression (3), so the retrieval expression (3) will not be used to retrieve meteorological it structures including these words.

As to existential there structure, the retrieval tool $[\mathrm{ex}]\left[\mathrm{vb}^{*}\right]$ is far beyond satisfaction, for the result will undoubtedly include some non-existential there structure like "And then there's Charles" (COCA_2015_ACAD). In view of this dilemma, I focus on three features that are enjoyed by existential there structures such as "being embedded", "negation", and "being questioned" (See Lakoff, 1987, p. 545). Then three retrieval expressions are set respectively for each of the above mentioned three features. For example:

(4) $[\mathrm{cs}]\left[[\mathrm{csa}]|[\mathrm{csn}]|[\mathrm{cst}]\left[[\mathrm{csw}]|[\mathrm{rrq}]|[\mathrm{rrqv}]|[\mathrm{vv} 0]|[\mathrm{vvd}]|[\mathrm{vvz}]|[\mathrm{vvg}] \mid[\mathrm{vvn}][\mathrm{ex}]\left[\mathrm{v}^{*}\right]\right.\right.$

(5) [ex] [vbdr]|[vbdz]|[vbr]][vbz]|[vd0]|[vdd]|[vdz]|[vh0]|[vhd]|[vm] [xx];

(6) [vbdr]|[vbdz]|[vbr]|[vbz]|[vd0]|[vdd]|[vdz]|[vh0]|[vhd]|[vm][[ex] [vb*]|[vv0]|[vvn]|[nn*]

Due to the fact that the results searched by retrieval expression (4) include some existential there structures with both being embedded and negative features, I set up retrieval expression (7) which aims to search those existential there structures with both being embedded and negative features. In this case, distribution frequency of existential there structures with the feature of being embedded can be obtained by subtracting the results of (7) from those of (4).

(7) $[\mathrm{cs}]|[\mathrm{csa}]|[\mathrm{csn}]|[\mathrm{cst}]|[\mathrm{csw}]|[\mathrm{rrq}]|[\mathrm{rrqv}]|[\mathrm{vv} 0]|[\mathrm{vvd}]|[\mathrm{vvg}]|[\mathrm{vvn}]|[\mathrm{vvz}][\mathrm{ex}][\mathrm{vbdr}]|[\mathrm{vbdz}]|[\mathrm{vbr}]|[\mathrm{vbz}]|[\mathrm{vd} 0]|[\mathrm{vdd}] \mid$

$$
[\mathrm{vdz}]|[\mathrm{vh} 0]|[\mathrm{vhd}] \mid[\mathrm{vm}][\mathrm{xx}]
$$

In addition, NPs in existential there structures are often modified by some modifiers, and then retrieval expression (6) has been revised as retrieval expression (8), (9), (10), and (11):

(8) $[\mathrm{vd} 0]|[\mathrm{vdd}]|[\mathrm{vdz}]|[\mathrm{vh} 0]|[\mathrm{vhd}]|[\mathrm{vm}][\mathrm{ex}][\mathrm{vb} *]|[\mathrm{vv} 0] \mid[\mathrm{vvn}]$

(9) $[\mathrm{vbdr}]|[\mathrm{vbdz}]|[\mathrm{vbr}] \mid[\mathrm{vbz}][\mathrm{ex}][\mathrm{nn} *]$

(10) $[\mathrm{vbdr}][[\mathrm{vbdz}]|[\mathrm{vbr}]|[\mathrm{vbz}][\mathrm{ex}][\mathrm{at} *][\mathrm{nn} *]$

(11) $[\mathrm{vbdr}][\mathrm{vbdz}][\mathrm{vbr}] \mid[\mathrm{vbz}][\mathrm{ex}][\mathrm{at} *]\left[\mathrm{j}^{*}\right][\mathrm{nn} *]$

\subsection{Results: Diachronic Distribution Frequencies of Formal Markers in COHA}

Now that the experiential phenomenon construed by multiple linguistic expressions has diversified linguistic expressions, the better way is to make a comparison among all linguistic expressions to see whether there exists a tendency towards formal marker structures. However, such a comparison is unnecessary, for in COHA with a large number of data the different types of linguistic expressions for the same experience construal should theoretically show more or less fixed distribution frequencies in each 10 years and in this case the increase of the distribution frequencies of formal markers means the decrease of other linguistic expressions. Therefore, whether there exists a conventional tendency towards formal marker structures among all linguistic expressions can be observed by the rise of distribution frequencies of formal markers in each 10 years in COHA. Since the results retrieved in COHA cannot really reflect the real situation, the distribution frequencies in each genre are then standardized. Therefore, the results given below are all standardized data. By retrieval expression (1-3), the results can be shown in Table 5. 
Table 5. Distribution frequencies of meteorological it in COHA (per million)

\begin{tabular}{|c|c|c|c|c|c|c|c|}
\hline Year & $\begin{array}{l}\text { rain } \\
\text { /ing } \\
/ y\end{array}$ & $\begin{array}{l}\text { snow } \\
\text { /ing } \\
/ y\end{array}$ & $\begin{array}{l}\text { thunder } \\
\text { /ing } \\
\text { /y }\end{array}$ & $\begin{array}{l}\text { hail } \\
\text { /ing } \\
\text { /ing }\end{array}$ & $\begin{array}{l}\text { freeze } \\
\text { /ing } \\
\text { /ing }\end{array}$ & $\begin{array}{l}\text { drizzle } \\
\text { /ing } \\
\text { /ing }\end{array}$ & Total \\
\hline $1810 \mathrm{~s}$ & 1.5597 & 0.0000 & 1.5597 & 0.0000 & 0.0000 & 0.0000 & 3.1194 \\
\hline $1820 \mathrm{~s}$ & 2.9324 & 1.0663 & 2.1326 & 0.0000 & 0.2666 & 0.0000 & 6.3979 \\
\hline $1830 \mathrm{~s}$ & 4.0841 & 0.3952 & 0.9222 & 0.5270 & 0.2635 & 0.0000 & 6.192 \\
\hline $1840 \mathrm{~s}$ & 3.1635 & 0.5649 & 1.1298 & 0.2260 & 0.7909 & 0.0000 & 5.8751 \\
\hline $1850 \mathrm{~s}$ & 3.7386 & 0.6598 & 0.5497 & 0.1100 & 0.3299 & 0.0000 & 5.388 \\
\hline $1860 \mathrm{~s}$ & 6.4546 & 0.7407 & 0.5291 & 0.3174 & 0.5291 & 0.1058 & 8.6767 \\
\hline $1870 \mathrm{~s}$ & 5.9270 & 1.6518 & 0.5830 & 0.1943 & 0.8745 & 0.0000 & 9.2306 \\
\hline $1880 \mathrm{~s}$ & 6.5091 & 1.0700 & 0.7133 & 0.2675 & 0.6242 & 0.0000 & 9.1841 \\
\hline $1890 \mathrm{~s}$ & 9.1864 & 1.6946 & 0.9811 & 0.2676 & 0.9811 & 0.0000 & 13.1108 \\
\hline $1900 \mathrm{~s}$ & 7.7310 & 2.1614 & 0.5820 & 0.1663 & 0.8313 & 0.0831 & 11.5551 \\
\hline 1910s & 9.2160 & 1.0892 & 0.7540 & 0.1676 & 0.5027 & 0.0000 & 11.7295 \\
\hline 1920s & 10.3671 & 3.5886 & 0.7975 & 0.4785 & 0.7975 & 0.0797 & 16.1089 \\
\hline 1930s & 13.8082 & 2.3575 & 0.3368 & 0.2526 & 1.0104 & 0.1684 & 17.9339 \\
\hline $1940 \mathrm{~s}$ & 10.7142 & 2.7623 & 0.5022 & 0.3348 & 0.2511 & 0.0000 & 14.5646 \\
\hline $1950 \mathrm{~s}$ & 11.5130 & 3.4205 & 0.5006 & 0.1669 & 1.3348 & 0.3337 & 17.2695 \\
\hline $1960 \mathrm{~s}$ & 9.8455 & 2.6773 & 0.3455 & 0.1727 & 0.4318 & 0.3455 & 13.8183 \\
\hline 1970s & 10.7509 & 3.6983 & 0.5160 & 0.1720 & 0.9461 & 0.2580 & 16.3413 \\
\hline $1980 \mathrm{~s}$ & 11.1087 & 2.5509 & 0.1646 & 0.0823 & 1.2343 & 0.1646 & 15.3054 \\
\hline 1990s & 14.1650 & 5.6509 & 0.5274 & 0.3014 & 1.0548 & 0.3014 & 22.0009 \\
\hline $2000 \mathrm{~s}$ & 10.5551 & 3.4955 & 0.4798 & 0.0000 & 1.4393 & 0.2056 & 16.1753 \\
\hline
\end{tabular}

Table 5 indicates that except the decrease of "thunder," all other types of meteorological it structures have a rising trend in 200 years ranging from 1810s to 2000s, especially the distribution frequencies of "rain", reaching 14.1650 times in 1990s, almost 10 times as much as that in 1810s. But it seems that there are some decreases in the distribution frequencies of meteorological $i t$ structures in some time period like 1900s, 1910s, 1940s, 1960s, 1980s, and 2000s. To test whether such a decrease will have an impact on the general rising trend in 200 years, I change Table 5 into Figure 1 and give the trend lines for meteorological it structures including "rain" and "snow".

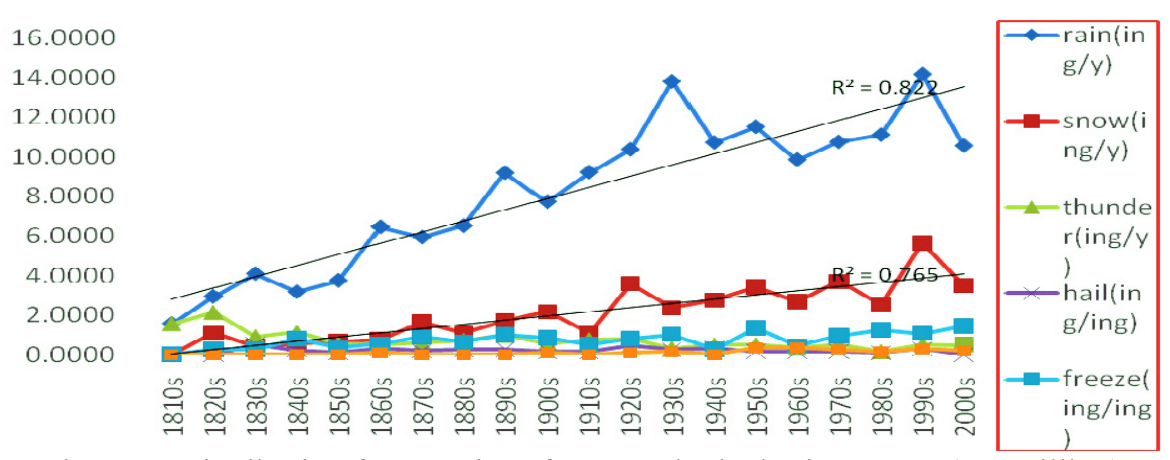

Figure 1. Distribution frequencies of meteorological it in COHA (per million)

Figure 1 indicates that the distribution frequencies of meteorological it structures including "rain" and "snow" have a linear fitting with $R^{2}$ equal to 0.8225 and 0.7656 respectively. The results show that there is a general rising tendency for meteorological it structures, though some decreases of the distribution frequencies of meteorological it structures exist in some time periods.

By retrieval expression (4-11), the results of all three types of existential there can be shown in Table 6 . 
Table 6. Distribution frequencies of existential there in COHA (per 10 thousand)

\begin{tabular}{|c|c|c|c|c|c|c|c|c|c|}
\hline \multirow{2}{*}{ Year } & \multicolumn{3}{|c|}{ Existential there } & \multirow{2}{*}{ Total } & \multirow{2}{*}{ Year } & \multicolumn{3}{|c|}{ Existential there } & \multirow{2}{*}{ Total } \\
\hline & Embedded & Negative & Questioned & & & Embedded & Negative & Questioned & \\
\hline $1810 \mathrm{~s}$ & 1.4037 & 0.4211 & 0.1092 & 1.934 & $1910 \mathrm{~s}$ & 3.5054 & 1.0934 & 0.1148 & 4.7136 \\
\hline $1820 \mathrm{~s}$ & 3.1243 & 0.5412 & 0.1999 & 3.8654 & $1920 \mathrm{~s}$ & 3.6038 & 1.1181 & 0.1260 & 4.8479 \\
\hline $1830 \mathrm{~s}$ & 3.2172 & 0.5757 & 0.1647 & 3.9576 & $1930 \mathrm{~s}$ & 3.3317 & 1.1164 & 0.0985 & 4.5466 \\
\hline $1840 \mathrm{~s}$ & 2.8822 & 0.5627 & 0.1819 & 3.6268 & $1940 \mathrm{~s}$ & 3.6336 & 1.2397 & 0.1113 & 4.9846 \\
\hline $1850 \mathrm{~s}$ & 3.3372 & 0.5916 & 0.1550 & 4.0838 & $1950 \mathrm{~s}$ & 3.4539 & 1.1296 & 0.1101 & 4.6936 \\
\hline $1860 \mathrm{~s}$ & 3.5448 & 0.7672 & 0.1619 & 4.4739 & $1960 \mathrm{~s}$ & 3.1583 & 1.0441 & 0.1365 & 4.3389 \\
\hline 1870s & 3.5261 & 0.8356 & 0.1496 & 4.5113 & $1970 \mathrm{~s}$ & 3.2476 & 0.9779 & 0.1359 & 4.3614 \\
\hline $1880 \mathrm{~s}$ & 3.7557 & 0.8658 & 0.1159 & 4.7374 & $1980 \mathrm{~s}$ & 3.1417 & 0.8681 & 0.1350 & 4.1448 \\
\hline $1890 \mathrm{~s}$ & 3.7557 & 0.9142 & 0.1534 & 4.8233 & $1990 \mathrm{~s}$ & 2.8398 & 0.8363 & 0.1221 & 3.7982 \\
\hline $1900 \mathrm{~s}$ & 3.6959 & 0.9227 & 0.1230 & 4.7416 & $2000 \mathrm{~s}$ & 2.6929 & 0.8088 & 0.1110 & 3.6127 \\
\hline
\end{tabular}

Table 6 indicates that embedded existential there has a rising trend from 1810s to 1890 s, while decreasing from 1950s. In the similar vein, negative existential there and questioned existential there show the similar trend. The former has a rising tendency and reaches the peak till 1940s while decreasing since then. The latter began to decrease from 1960s. To test the general rising trend of existential there in its distribution frequenciesin 200 years, Table 6 has been changed into Figure 2 with the trend line for the distribution frequencies of each existential there type.

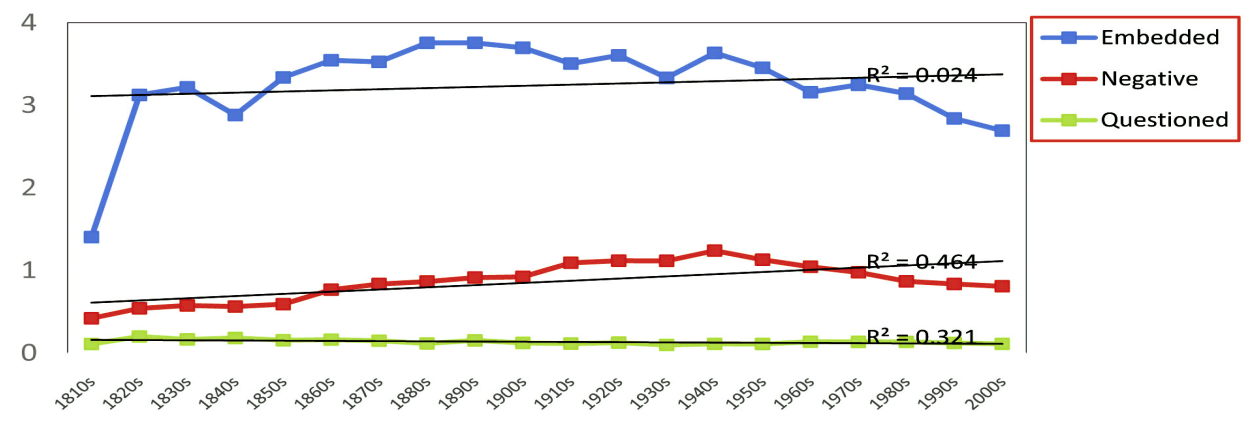

Figure 2. Distribution frequencies of existential there in COHA (per 10 thousand)

Figure 2 indicates that except the higher $R^{2}$ for negative existential there, embedded and questioned existential there have a lower $R^{2}$, especially $R^{2}(=0.0241)$ for embedded existential there, which shows that the trend cannot be a linear fitting.

In order to reflect the general trend of both meteorological it structures and existential there structures, all those types of formal markers are combined together respectively. Given that meteorological it structures have lower distribution tendencies as opposed to existential there structures, the distribution frequencies of existential there are standardized as per million for the convenience of showing the distribution frequenciesof meteorological it structures and existential there structures together.

Table 7. Distribution frequencies of meteorological it and existential there in COHA

\begin{tabular}{|c|c|c|c|c|c|c|c|c|c|}
\hline \multirow[b]{2}{*}{ Year } & \multicolumn{2}{|c|}{ Meteorological it } & \multicolumn{2}{|c|}{ Existential there } & \multirow[b]{2}{*}{ Year } & \multicolumn{2}{|c|}{ Meteorological it } & \multicolumn{2}{|c|}{ Existential there } \\
\hline & $\mathrm{DF}$ & $\begin{array}{l}\text { SD (per10 } \\
\text { million) }\end{array}$ & $\mathrm{DF}$ & $\begin{array}{l}\text { SDF (per } \\
\text { million) }\end{array}$ & & $\mathrm{DF}$ & $\begin{array}{c}\text { SD (per10 } \\
\text { million) }\end{array}$ & $\mathrm{DF}$ & $\begin{array}{c}\text { SDF (per } \\
\text { million) }\end{array}$ \\
\hline $1810 \mathrm{~s}$ & 2 & 31.19 & 124 & 193.40 & $1910 \mathrm{~s}$ & 140 & 117.30 & 5626 & 471.36 \\
\hline $1820 \mathrm{~s}$ & 24 & 63.98 & 1450 & 386.54 & $1920 \mathrm{~s}$ & 202 & 161.09 & 6079 & 484.78 \\
\hline $1830 \mathrm{~s}$ & 47 & 61.92 & 3004 & 395.77 & $1930 \mathrm{~s}$ & 213 & 179.34 & 5400 & 454.66 \\
\hline $1840 \mathrm{~s}$ & 52 & 58.75 & 3210 & 362.68 & $1940 \mathrm{~s}$ & 174 & 145.65 & 5955 & 498.46 \\
\hline $1850 \mathrm{~s}$ & 49 & 53.88 & 3714 & 408.39 & $1950 \mathrm{~s}$ & 207 & 172.70 & 5626 & 469.36 \\
\hline $1860 \mathrm{~s}$ & 82 & 86.77 & 4228 & 447.38 & $1960 \mathrm{~s}$ & 160 & 138.18 & 5024 & 433.89 \\
\hline $1870 \mathrm{~s}$ & 95 & 92.31 & 4643 & 451.13 & $1970 \mathrm{~s}$ & 190 & 163.41 & 5071 & 436.14 \\
\hline $1880 \mathrm{~s}$ & 103 & 91.84 & 5313 & 473.74 & $1980 \mathrm{~s}$ & 186 & 153.05 & 5037 & 414.48 \\
\hline $1890 \mathrm{~s}$ & 147 & 131.11 & 5408 & 482.33 & $1990 \mathrm{~s}$ & 292 & 220.01 & 5041 & 379.82 \\
\hline $1900 \mathrm{~s}$ & 139 & 115.55 & 5704 & 474.17 & $2000 \mathrm{~s}$ & 236 & 161.75 & 5271 & 361.27 \\
\hline
\end{tabular}

Note. $\mathrm{DF}=$ distribution frequency; $\mathrm{SDF}=$ standardized distribution frequency. 
Table 7 indicates that the distribution frequencies of meteorological it structures with an interval of decease have a general rising trend since $1810 \mathrm{~s}$, while existential there shows a decrease in its distribution frequencies after reaching the peak 498.46 in $1950 \mathrm{~s}$. To test whether these decrease trends have an impact on the general rising tendency, Table 7 has been changed into Figure 3 with the trend line as well as value of $R^{2}$.

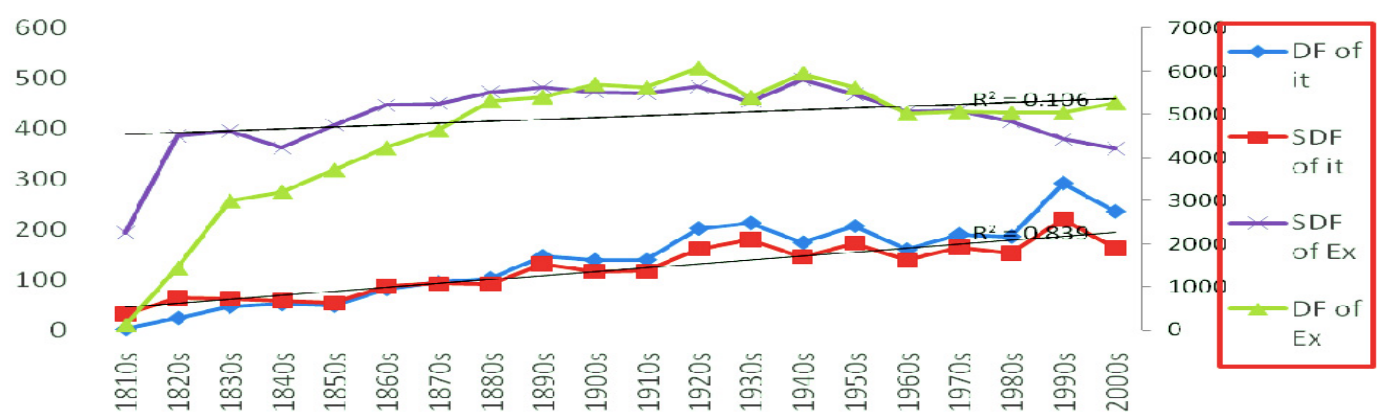

Figure 3. Distribution frequencies of meteorological it and existential there in COHA

Note: $\mathrm{DF}=$ distribution frequency; $\mathrm{SDF}=$ standardized distribution frequency; $\mathrm{Ex}=$ there.

Figure 3 indicates that formal marker it can be a linear fitting with the value of $R^{2}(=0.8395)$, which means a rising trend in the distribution frequencies in COHA. However, the value of $R^{2}$ for existential there is only 0.106 , which means that the trend for the distribution frequencies of existential there is a hyperbolic curve rather than a linear. The cause for such a trend is that the distribution of frequencies of existential there began to fall since $1950 \mathrm{~s}$, which is against the assumption of rising trend with time going on. But a careful observation reveals that such a falling tendency results from the unbalanced data in COHA. For instance, during the period of 1950s to 2000s, the data about "story" and "novel" have increased while the data on "drama" and "film" have decreased. Compared with "story" and "novel", "drama" and "film" are featured by the interpretive language, which is similar to academic genre and requires formal markers to play a role in its construction (See Dong, 2016). However, formal marker it has not been impacted, for the increase of "story" and "novel" will entail the introduction to the weather, which in turn increase the distribution frequencies of formal marker it. In this case, if the data ranging from 1810 s to 1940 s is considered only, the rising trend exists in both formal markers it and there (See Figure 4).
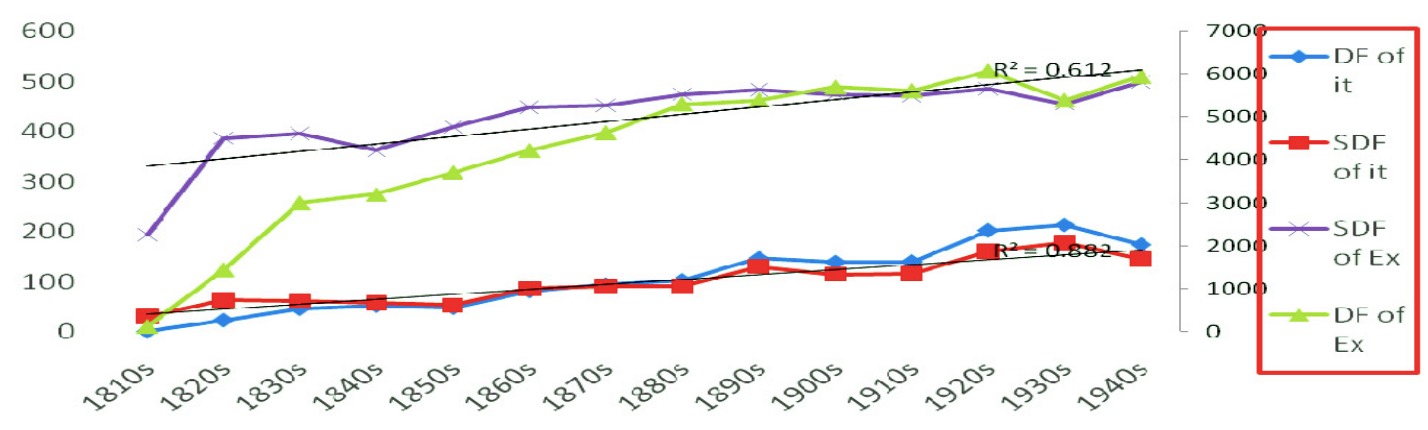

Figure 4. Distribution frequencies of meteorological it and existential there in COHA

Note: $\mathrm{DF}=$ distribution frequency; $\mathrm{SDF}=$ standardized distribution frequency; $\mathrm{Ex}=$ there.

Figure 4 indicates that the distribution frequencies in both formal markers it and there have a linear fitting with the value of $R^{2}$ equal to 0.8823 and 0.6127 respectively, which shows that there is a general rising tendency for both formal markers it and there ranging from $1810 \mathrm{~s}$ to $1940 \mathrm{~s}$.

\section{The Motive of Crypto-Function of Formal Markers: Prefabricate Potential in Experience Construction}

\subsection{Experience Construction and Language Choice}

In SFL, Construing Experience Through Meaning collaborated by Halliday \& Matthiessen (1999) can be rendered as a classic monograph addressing the issue of experience construction. According to Halliday \& 
Matthiessen (1999, p. 17), meaning does not pre-exist but is constructed simultaneously, i.e., the constructivist view on language in SFL. Meanwhile, language is the source for experience construction (ibid, 1999, p. 15), that is, experience is construed by meaning via language. In reality, experience construction is twofold: language as construing material in experience construction and the choices among these linguistic materials. As indicated in section 2.1, the crypto-function of formal markers can be revealed by observing the conventionalization of multiple linguistic expressions towards formal markers in their construction of the experiential phenomenon. Therefore, the latter will be the focus of this section.

SFL puts great emphasis on the idea of language as a system of choices, which can also be embodied in experiential phenomenon like "weather" and "existence". As one of multiple linguistic expressions for construing experience phenomenon, formal markers together with other linguistic expressions construct the same experience phenomenon, but which one is chosen to construct experience phenomenon is concerned about language choice. To some extent, "any one selection from within this range of options could be realized through a wide range of different grammatical categories and lexical items" (Halliday, 1973, p. 60), though the interpersonal and textual functions might vary. In order to elaborate on this view, Halliday (1973, p. 60) discusses how experience about "authority", "general" and "object-oriented" is constructed among options in language system, as shown in (12).

(12) a. That sort of place is not for playing in.

b. We don't go into places like that.

c. Other people's things aren't for playing with.

d. We don't like take other people's property.

Surely, such linguistic expressions cannot be the whole list. But one thing is sure, that is, all the linguistic expressions should center on the semantic contents like "authority", "general" and "object-oriented". Of course, such semantics contents can be sub-categorized, and then a somewhat more detailed list of linguistic expressions can be obtained. In the same vein, the more abstract list of linguistic expressions can be attained if the semantic content is generalized.

By the same token, experiential phenomenon like "weather" and "existence" can also be constructed in multiple linguistic expressions, which can then form a systemic network. See Figure 5, 6.

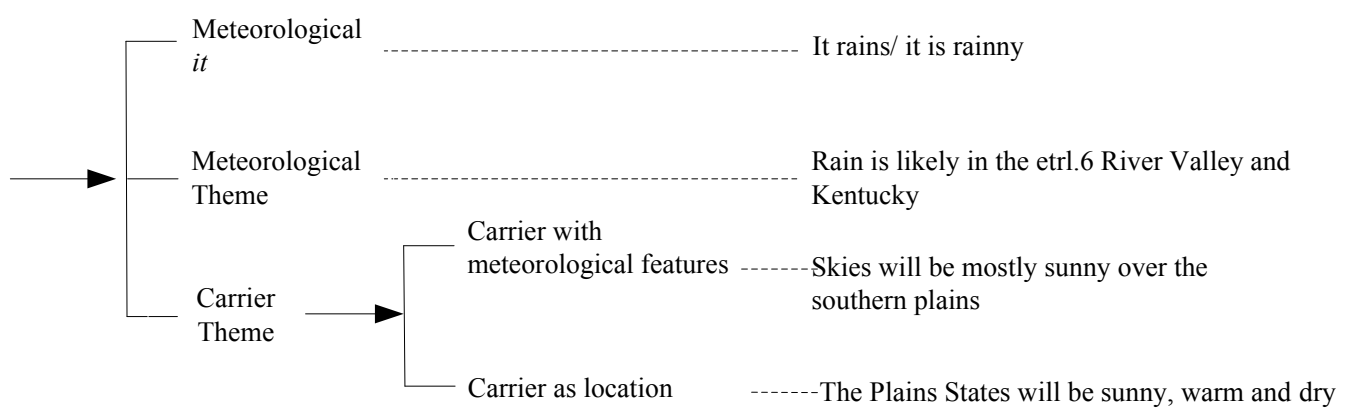

Figure 5. Part of meteorological system (cf. Halliday \& Matthiessen, 1999, p. 342)

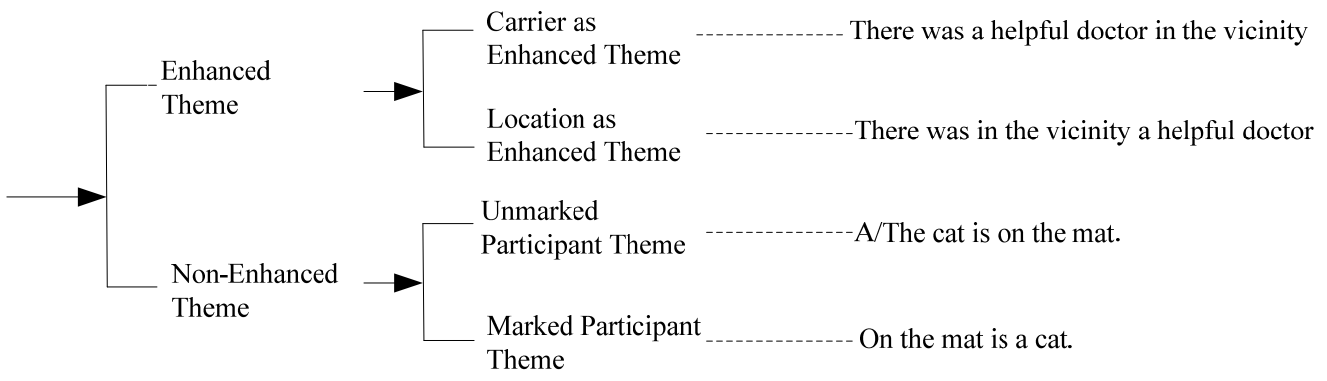

Figure 6. Existential systemic network (cf. Deng, 2005, pp. 39-46) 
In this case, the construction of the experiential phenomenon like "weather" and "existence" is the process of language choice in systemic network as indicated in Figure 5 and 6. In other words, the process of the experience construction is also the process of language choice. And the distribution frequencies of formal markers reflected by the results in 3.2 indicates that, among the multiple linguistic expressions, formal markers it and there ranging from 1810 s to 1940 s enjoy the preference, which means that the diachronic conventionalization of multiple linguistic expressions towards formal markers does exist. It is worthy of noting that such a conclusion is based on a presupposition, i.e., in COHA with enormous data all linguistic expressions for the same experience construal should more or less show the fixed distribution frequencies in each 10 years and in this case the increase of the distribution frequencies of formal markers means the decrease of other relevant linguistic expressions.

\subsection{Formal Markers as Prefabricate Potential in Their Construction of Experiential Phenomenon}

Based on the results of the conventionalization of multiple linguistic expressions diachronically towards formal markers in 3.2, I argue that formal markers can be treated as prefabricate potential. By prefabricate potential, I mean that formal markers together with other elements form a potential language chunk to construct the experience. Therefore, prefabricate potential in experience construction shows a quite different performance as opposed to any other linguistic element. The latter constructs the experience as an individual element rather than integrating with other linguistic elements. Such a distinct can be well demonstrated by the construction of the experiential phenomenon like "weather" and "existence" in the form of formal markers and in the form of general element. It is worthy of noting that the construction of experience is a process of turning experience into meaning with lexicogrammar as a power house. Therefore, the experience construction can be divided into two layers, that is, the change of experience into meaning in ideational base and the realization of meaning as linguistic expressions in lexicogrammar, respectively. The former is embodied as "sequence", "figure", and "element", which is realized in the latter by "clause complex", "clause", "phrase or group", respectively.

(13) a. [clause [group] The rain $_{\text {[group] }}$ is raining].

b. [clause [group] $A$ book ${ }_{\text {[group] }}$ is [group] $_{\text {on the }}$ desk].

(14) a. [clause [sub-clause] It is raining .

b. [clause [sub-clause] $T$ There is a book [group] $_{\text {on the }}$ desk] $_{\text {] }}$.

It is well demonstrated that in (13) the construction by general element is based on "phrase or group", while the construction by formal markers can be regarded as a language chunk in lexicogrammar, i.e., in the form of "sub-clause". If there is no element in the experience of construction, the "sub-clause" can thus be equal to a "clause".

Though the construction of experience is completed in lexicogrammar, the lexicogrammar can only be the materials of construction, and the meaning is the focus of construction, which is the rationale why Halliday \& Matthiessen (1999) give the book such a title as Construing Experience Through Meaning. Therefore, in ideational base formal markers it and there serve as "element" in the construction of experience. In the same vein as its construction in lexicogrammar, formal markers in the experience construction in ideational base are also with other "element" to form a semantic chunk, that is, "sub-figure". If there is no other element in the experience of construction, the "sub-figure" can thus be equal to a "figure".

(15) a. [figure [element] The rain ${ }_{\text {[element] }}$ is raining].

b. [figure [element] $\mathrm{A}$ book [element] $^{\text {is }}{ }_{\text {[element] }}$ on the desk . $_{\text {. }}$.

(16) a. [figure [sub-figure] It is raining].

b. [figure [sub-figure] $T$ There is a book ${ }_{\text {[element] }}$ on the desk $_{\text {] }}$.

But how formal markers can be formed as a prefabricate potential in lexicogrammar and in ideational base, that is, "sub-clause" and "sub-figure" respectively, I argue, lies in two aspects. First, formal markers have a prediction role in deciding the element that follows no matter they are in lexicogrammar or in ideational base. In other words, once the formal markers embodied as "elements" of "figure" or as "groups" of "clause" are set, the following element embodied as "elements" of "figure" or as "groups" of "clause" can be set accordingly. Second, formal markers, though they can be used as a single element in experience construction, often depend on other elements to play a role, for their semantic contents are quite weak. This might be the possible reason why Thompson (2004, p. 262) put formal marker it and Process together in its experiential function analysis.

In the meantime, the idea of formal markers as a prefabricate potential can be evidenced by some studies about language chunks. Though formal markers cannot be called language chunk, the features of language chunk like 
multiple words, frequency, prediction between elements, prefabricate potential (See Yi \& Lu, 2013, p. 2110) do shed some light on formal markers. In this case, the possibility of how formal markers are chosen in language system can be enlightened by the retrieval of language chunk. In a reading process study conducted by Tremblay et al. (2009), the results reveal that those sentences with language chunks can be processed much faster than those without (quoted from Yi \& Lu, 2013, p. 2112). In this case, within the multiple linguistic expressions for construing experience, formal markers as prefabricate potential and with the feature of language chunk will undoubtedly enjoy the preference, which is in line with the results shown in section 3 . That is, among the multiple linguistic expressions, formal markers it and there ranging from 1810s to 1940s enjoy the preference, which means that the diachronic conventionalization of multiple linguistic expressions towards formal markers does exist.

It is such a prefabricate potential enjoyed by formal markers that leads to the conventionalization of multiple linguistic expressions towards formal markers. In the meantime, the prefabricate potential leads to the higher degree of conventionalization on the one hand; and such a conventionalization can further lead to the prefabricate potential of formal markers on the other. And such a conventionalization makes the formal markers have the reactance which other elements lack, and finally results in crypto-function. Therefore, the motive to the crypto-function of formal markers can be attributed to their prefabricate potential or "grammatical and subjective mode" in Martínez-Insua (2013, p. 220) term. Perhaps someone will argue that the motive to the crypto-function of formal markers should be explored from the earliest year when formal markers came into being, thus the discussion in this paper becomes less convinced. However, given the polysemous relationship between formal markers and their counterparts (See Dong, 2016), the exploration of the motive of crypto-function of formal markers is to understand how the formal markers separate from non-formal markers alongside the semantic cline, which can thus be located in any diachronic time span. In light of this, ever since formal markers come into being, their crypto-functions can be observed through their prefabricate potential, and such a prefabricate potential will become much more apparent with the time passing by. In this case, the diachronic approach adopted in this study can be viewed as an epitome of formal markers along their evolution path, and the exploration of the crypto-function of formal markers by treating formal markers as prefabricate potential is sensible.

\section{Summary}

Given that formal markers have the reactance that their counterparts are devoid of, formal markers can be treated as the crypto-category (See Whorf, 1956) and their functions can thereby be analyzed as crypto-functions (See Dong, 2016). This paper, however, goes ever further in an attempt to locate the motive of crypto-functions of formal markers. The study firstly assumes that the crypto-functions of formal markers are related to the conventionalization of multiple linguistic expressions towards formal markers in their construction of experience phenomenon. Then such an assumption is well proved by the data of the distribution frequencies of formal markers in COHA. The findings are (i) that the diachronic conventionalization of multiple linguistic expressions towards formal markers does exist in terms of the diachronic increase of the distribution frequencies of formal markers in COHA, and (ii) that such a conventionalization is then attributed to language chunk consisting of formal markers and other following elements and renders formal markers the prefabricate potential, thus resulting in their crypto-functions.

\section{Acknowledgements}

This paper is part of the achievements supported by Humanistic \& Social Science Research Program of Chongqing Municipal Education Commission (15SKG188) and the Research Fund of Chongqing University of Science \& Technology (CK2014Z08).

\section{References}

Deng, R. (2005). A systemic functional approach to existential clauses in English. Journal of Foreign Languages, (5), 39-46.

Dong, B. (2016). Towards the Crypto-Functions of Independent Formal Markers in English: A Systemic Functional Perspective (Unpublished doctoral dissertation). Southwest University, Chongqing, China.

Dong, B., \& Wang, L. (2016). Towards a functional approach to the formal markers' metafunctional analysis. Foreign Languages in China, (2), 72-80.

Fawcett, R. P. (1999). On the subject of the Subject in English: two positions on its meaning (and on how to test for it). Functions of Language, 6(2), 243-273. http://dx.doi.org/10.1075/fol.6.2.05faw

Halliday, M. A. K. (1973). Explorations in the Functions of Language. London: Edward Arnold. 
Halliday, M. A. K. (1994). An Introduction to Functional Grammar (2nd ed.). London: Edward Arnold.

Halliday, M. A. K., \& Matthiessen, C. M. I. M. (2004). An Introduction to Functional Grammar (3rd ed.). London: Edward Arnold.

Halliday, M. A. K., \& Matthiessen, C. M. I. M. (2014). An Introduction to Functional Grammar (4th ed.). London \& New York: Routledge.

Halliday, M. A. K., \& Matthiessen, I. M. C. M. (1999). Construing Experience through Meaning: A Laguage-based Approach to Cognition. London and New York: Cassell.

Lakoff, G. (1987). Women, Fire, and Dangerous Things. Chicago: University of Chicago Press. http://dx.doi.org/10.7208/chicago/9780226471013.001.0001

Langacker, R. W. (1991). Foundations of Cognitive Grammar, Vol. 2: Descriptive Application. Stanford: Stanford University Press.

Levin, B. (1993). English Verb Classes and Alternations: A Preliminary Investigation. Chicago \& London: The University of Chicago Press.

Martin, J. R. (2013). Interviews with M. A. K. Halliday. London \& New York: Bloomsbury Academic.

Martínez-Insua, A. E. (2013). There-constructions as a choice for coherence in the recent history of English. In L. Fontaine, T. Bartlett, \& G. O'Grady (Eds.), Systemic Functional Linguistics: Exploring Choice (pp. 207-225). Cambridge: Cambridge University Press. http://dx.doi.org/10.1017/CBO9781139583077.014

Sinclair, J. (1990). Collins COBUILD English Grammar. London: William Collins Son \& Co Ltd.

Thompson, G. (2004). Introducing Functional Grammar (2nd ed.). London: Arnold.

Whorf, B. L. (Ed.). (1956). Language, Thought and Reality: Selected Writings of Benjamin Lee Whorf. Cambridge, Mass.: M. I. T. Press.

Yi, W., \& Lu, S. (2013). The psychological reality of formulaic language. Advances in Psychological Science, (12), 2110-2117. http://dx.doi.org/10.3724/SP.J.1042.2013.02110

\section{Copyrights}

Copyright for this article is retained by the author(s), with first publication rights granted to the journal.

This is an open-access article distributed under the terms and conditions of the Creative Commons Attribution license (http://creativecommons.org/licenses/by/3.0/). 